\title{
Simple Machines and Chain Reactions using OK Go's "This Too Shall Pass" Music Video (Resource Exchange)
}

\section{Dr. AnnMarie Thomas, University of St. Thomas}

AnnMarie Thomas is a professor in the School of Engineering at the University of St. Thomas where she is the director of the UST Center for Engineering Education. Her research group, the Playful Learning Lab, focuses on engineering and design education for learners of all ages.

\section{Dr. Deborah Besser P.E., University of St. Thomas}

Dr. Besser, PE, ENV SP, holds a PhD in education and MS and BS in civil engineering. Currently, she is civil engineering chair and Center for Engineering Education director. Previous experience includes faculty positions in diverse universities where she has taught a variety of coursework including steel, timber, concrete and masonry design, construction, engineering economy, engineering graphics and engineering education. Prior to teaching, Dr. Besser, a licensed engineer, was a design engineer with HNTB-CA, where she worked on seismic retrofits and new design of high profile transportation structures.

\section{Jenna Laleman, University of St. Thomas}

Jenna is a senior at the University of St. Thomas, finishing up her Bachelor's Degree in Elementary Education and STEM Education with a minor in Psychology. Jenna collaborates with the Center for Engineering Education to create outreach curriculum. She works in her university's Playful Learning Lab which focuses on engaging students of all ages in hands-on, innovative engineering education, especially focusing on reaching the underrepresented within the STEM fields. Jenna also leads the University's STEPS (Science, Technology, and Engineering Preview Summer) Program, developing the curriculum, leading the staff, and working as the primary researcher.

\section{Maria Baklund, University of St. Thomas}

Undergraduate Research Assistant for the Playful Learning Lab at St. Thomas under the direction of Dr. Annmarie Thomas. Second-year Mechanical Engineering major with a Peace Engineering minor. Has led many STEM activities and is interested in using engineering to encourage peoples' interests and collaborate with developing countries.

\section{Miss MiKyla Jean Harjamaki, Playful Learning Lab}

I am an undergraduate student studying mechanical engineering and math and the University of St. Thomas. I am the lab operations manager at the Playful Learning Lab

\section{Esmée Verschoor, Playful Learning Lab}

Esmée Verschoor is a Communications and Journalism major at the University of St. Thomas in St. Paul, Minnesota. She is passionate about graphic design, visual communication and cultural studies. Currently, Esmée is the Visual Manager at the Playful Learning Lab, led by Dr. AnnMarie Thomas, where she creates, designs and implements educational materials focused on incorporating joy, whimsy and play into education. 


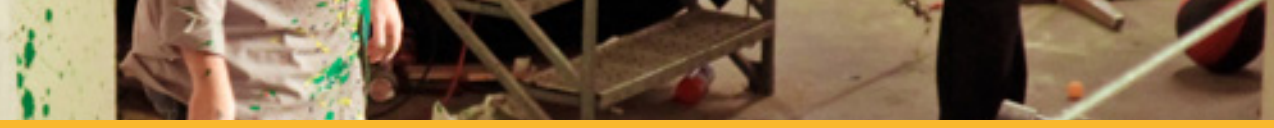

\section{SIMPLE MACHINES AND CHAIN REACTIONS}
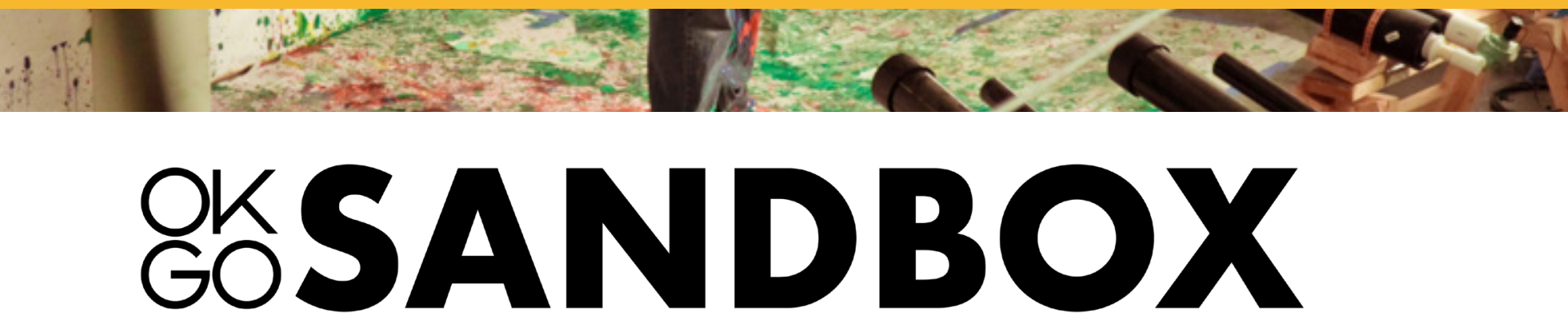

OKGoSandbox.org

Playful Learning Lab, University of St. Thomas

Dr.Annmarie Thomas apthomas@stthomas.edu

\section{INTRODUCTION}

Anything created using engineering design process stems from the ideas found in simple machines (i.e. wheels, axles, levers, incline planes, pulleys, wedges and screws).

The purpose of this resource is to teach the idea of mechanical advantage, and demonstrate the importance of different kinds of simple machines.

Mechanical advantage is the idea that one can input lesser amounts of force and result with an output of greater force. The ratio between the applied and resultant forces is the quantifiable definition of mechanical advantage.

Resource Time: 45-75 min or Two Class Periods

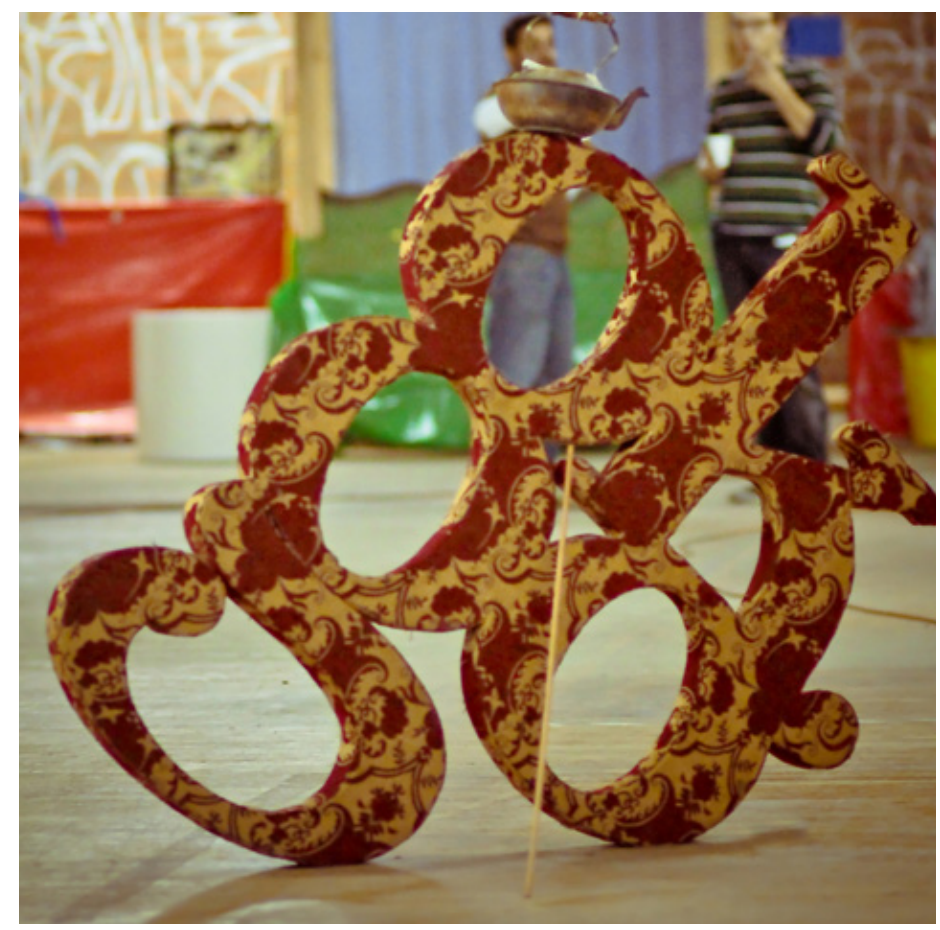

\section{LEARNING OBJECTIVES}

Identify the six different kinds of simple machines, and how they utilize mechanical advantage Understand how simple machines work within chain reaction machines and everyday life Strengthen teamwork skills through an engineering design challenge 


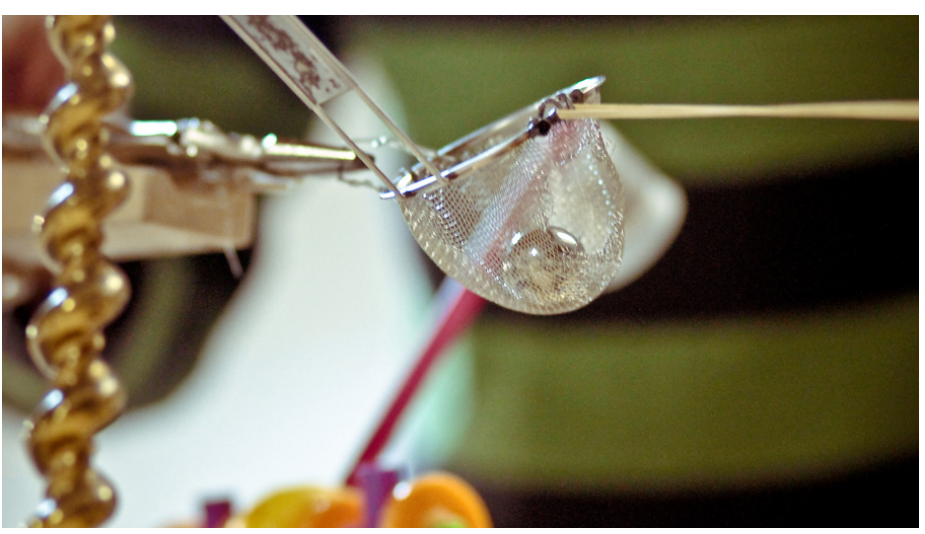

Bring in items yourself and/or encourage students to bring items from home

e.g. marbles, tape, toy cars, string, paper cups, tubes, cardboard etc.

Play OK Go "Simple Machines Scavenger Hunt" Challenge video on OKGoSandbox.org. (Time 2:23 min)

Ask your students to find an example of each kind of simple machine and write it down using the following OK Go music video.

Play OK Go's "This too Shall Pass" music video (Time 3:53 min)

It's likely that some students won't find all six types, prompt them to talk to their neighbors and then start a class discussion to talk about some of their examples.

(Start of Optional Second Day)

Explain the concept of chain reaction machines: simple machines combined together to form a multistep process that may or may not end by completing a basic task.

Have the students split into groups of 3-5. Challenge the students to use two or more types of simple machines to create their own chain reaction machine. If desired you can further challenge students to complete the same basic task (e.g. opening a book, pouring something into a bowl, put a ball into a basket, etc.)
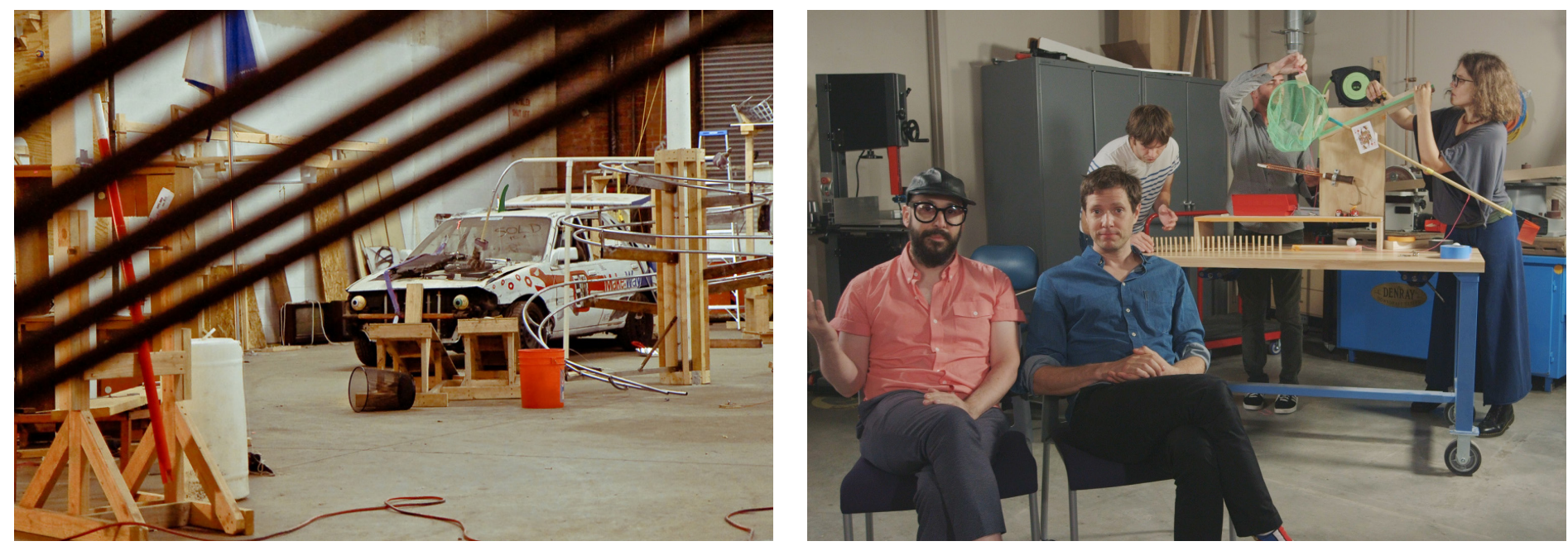